\section{Comparison of bone marrow aspirate cytology, touch imprint cytology and trephine biopsy for bone marrow evaluation}

\author{
Smita Chandra, Harish Chandra \\ Department of Pathology, Himalayan \\ Institute of Medical Sciences, \\ Uttarakhand, India
}

\section{Abstract}

Studies have compared the role of bone marrow aspirate cytology and trephine biopsy for diagnosing various hematological disorders but fewer studies have compared the relative value of imprint cytology with aspirate and trephine biopsy. The present study was conducted to compare the role of bone marrow aspirate, touch imprint and trephine biopsy to formulate an effective and rapid method for diagnosing wide spectrum of hematological diseases. The study included total 565 cases of bone marrow examination from January 2006 till May 2010. All the smears and sections were reviewed for morphological details and findings on aspirate, imprint and biopsy were compared to each other. The diagnostic accuracy of bone marrow aspirate was $77.5 \%$, imprint cytology $83.7 \%$ and that of biopsy was of $99.2 \%$. The study showed $78 \%$ positive correlation between aspirate and biopsy and $84.3 \%$ between imprint and biopsy; $93.3 \%$ cases of metastatic solid tumors were correctly diagnosed on imprint while only $70 \%$ cases were diagnosed on aspirate cytology. The study concludes that all the three preparations of aspirate, imprint and biopsy complement each other. The assessment of iron status by Perl's stain is most suitable on aspirate smears but trephine biopsy remains the gold standard for diagnosing granulomatous inflammation and hypoplastic/ aplastic anemia. Meticulously prepared imprint smears not only provide cellular composition of marrow but may also be helpful in defining the architecture of marrow especially in cases of metastatic solid tumors. Imprint cytology smears should be standard practice for evaluating any marrow.

\section{Introduction}

Bone marrow examination is an important diagnostic tool to evaluate various disorders including both neoplastic and non neoplastic hematological diseases. The bone marrow evaluation may either confirm clinically suspected disease or may provide the previously unsuspected diagnosis. ${ }^{1,2}$ Bone marrow aspirate cytology (BMA), touch imprint cytology (BMI) and trephine biopsy (BMB) are the three main basic preparations for bone marrow evaluation. Although studies have compared the role of bone marrow aspirate cytology and trephine biopsy for diagnosing various hematological disorders but fewer studies have compared the relative value of imprint cytology with aspirate and trephine biopsy. ${ }^{3-5}$ The present study was therefore conducted to compare the role of bone marrow aspirate cytology, touch imprint cytology and trephine biopsy to formulate an effective and rapid method for diagnosing wide spectrum of hematological diseases.

\section{Materials and Methods}

The study was conducted in the hematology laboratory of the institute which included total 565 cases of bone marrow examination from January 2006 till May 2010. Only these cases in which bone marrow examination was done by using all the three methods of BMA, BMI and BMB were included in the study. The standard technique was employed for obtaining the aspirate samples using the Salah's needle from posterior superior iliac spine. The trephine biopsy was performed using Jamshidi needle with the length of the biopsy core ranging from 1 to $3 \mathrm{~cm}$. The biopsy was then fixed for minimum of $24 \mathrm{~h}$ in $10 \%$ buffered formalin and then decalcified overnight in mixture of $8 \%$ hydrochloric acid and $10 \%$ formic acid in equal amounts. Before fixation of the biopsy minimum five touch imprint smears were prepared by using the procedure of gentle touch and rolling of the biopsy core on the slide. The fixation of the biopsy core was followed by automated tissue processing, paraffin embedding and sectioning. All the aspirate and touch imprint smears were routinely stained by Jenner Giemsa while the trephine biopsy sections were stained by routine Hematoxyline Eosin stain along with reticulin stain. Perl's iron stain was performed for every case on BMA, BMI smears and BMB sections. The relevant cytochemistry and immunochemistry staining was performed as and when required. In 4 cases of suspected metastasis bilateral trephine biopsy was performed. All the smears and sections were reviewed for morphological details by two pathologists and the findings on BMA, BMI and BMB were compared to each other for final diagnosis.

\section{Results}

A total of 565 cases underwent bone marrow
Correspondence: Harish Chandra, Himalayan Institute of Medical Sciences, Swami Ram Nagar Doiwala, Dehradun-248140, Uttarakhand, India.

Tel. +91.9411718442 .

E-mail: drharishbudakoti31@yahoo.co.in

Key words: bone marrow aspirate, imprint cytology, trephine biopsy.

Contributions: SC, study conception and design, data collection and interpretation, manuscript writing; HC, data collection and interpretation, manuscript evaluation.

Conflict of interest: the authors report no conflicts of interest.

Received for publication: 9 August 2011. Accepted for publication: 12 October 2011.

This work is licensed under a Creative Commons Attribution NonCommercial 3.0 License (CC BYNC 3.0).

(OCopyright S. Chandra and H. Chandra, 2011

Licensee PAGEPress, Italy

Hematology Reports 2010; 3:e22

doi:10.4081/hr.2011.e22

examination from January 2006 till May 2010 in which all the three types of preparation including BMA, BMI and BMB were made. Out of these 438 cases were diagnosed on BMA with diagnostic accuracy of $77.5 \% .473$ cases were diagnosed on BMI with diagnostic accuracy of $83.7 \%$ and 561 cases were diagnosed on BMB with diagnostic accuracy of $99.2 \%$. Table 1 shows the total cases diagnosed on BMA, BMI and BMB. It shows that none of the cases of granulomatous inflammation and hypoplastic/aplastic anemia was diagnosed on BMA and BMI cytology. Anemia of chronic disorder was the only group of disease in which 4 cases out of total 22 cases were not diagnosed on BMB while all the 22 cases were diagnosed on BMA. Table 2 shows the cases having positive correlation between BMA cytology and BMB sections and between BMI cytology and BMB sections. It shows that $78 \%$ cases showed positive correlation between BMA and BMB while $84.3 \%$ cases showed positive correlation between BMI and BMB. Table 3 shows the cases where findings on BMA, BMI and BMB differed from final diagnosis. It shows that hematological malignancies which were not diagnosed on BMA were either due to dry tap because of fibrosis or packed marrow. Perl's iron stain demonstrated reduced or no iron in 10 cases on BMI and 4 cases on BMB while all 22 cases showed iron on BMA. Two cases of positive metastatic solid tumors on BMB showed normal or hypocellular marrow on BMI and 8 cases were normal or hypocellular on BMA cytology. 


\section{Discussion}

The comparative evaluation of BMA, BMI and BMB is essential so that more rapid and efficient method may be defined for diagnosing various hematological disorders. The present study observed that although the diagnostic accuracy of BMB was highest (99.2\%) but diagnostic accuracy of BMI was also considerably high $(83.7 \%)$ in comparison to BMA (77.5\%) in diagnosing various hematological disorders. This is in contrast to other studies which have observed imprint cytology to be of limited valve except in cases of dry tap. ${ }^{5}$ The efficacy of BMI cytology observed in the study was specially related to diagnosis of metastatic solid tumors (Figure 1) and lymphomas. 93.3\% cases of metastatic solid tumors were correctly diagnosed on BMI cytology in comparison to $70 \%$ cases on BMA in the study. However, BMB was the standard procedure which diagnosed all the cases of metastatic solid tumors. Donald et al. have also reported that on comparative evaluation of BMA, BMI and BMB, the aspirate was positive in $33 \%$ cases, touch imprints in $90 \%$ cases and biopsy sections were positive in all the cases. ${ }^{6}$ Although studies have shown that trephine biopsy was 2.6 times positive compared to aspirate for detection of metastasis but the present showed that meticulously prepared imprint smears with close search of metastatic cells on aspirate smears could have diagnostic accuracy $(93.3 \%)$ almost similar to that of trephine biopsy (100\%). The authors also suggest that detection of metastatic cells on BMI in suspected cases can be increased by performing bilateral bone marrow examination which can detect focal involvement of marrow also. In the present study lymphoma was diagnosed in all cases on BMB but touch imprints also considerably increased the chances of detection of lymphoma cells (88.2\%) in comparison to BMA smears (52.9\%) (Figure 2). Aboul Nasr R et al. have also observed that lymphoma cells were easily detected in all cases on touch imprints while in $83 \%$ cases lymphoma cells were observed on aspirate smears. ${ }^{7}$ This is in contrast to other studies which observed that touch imprints do not improve the ability to diagnose lymphoma cells in comparison to aspirate smears. ${ }^{8,9}$ The authors suggest that although the tophographical arrangement of lymphoma cells are best seen on biopsy sections but this arrangement can also be well appreciated in meticulously prepared touch imprint cytology smears. Another interesting feature that was observed in the study was that Perl's iron stain was best demonstrated on aspirate smears in comparison to imprint smears and biopsy sections. The probable cause may be due to loss of iron during processing of biopsy sections. This was the possi- ble reason that the anemia of chronic disorder was not diagnosed in 4 cases on BMB and thus reducing the diagnostic accuracy of BMB to 99.3\%. However another study has observed BMB to have significantly higher positivity

rate for assessing iron stores in comparison to smears. ${ }^{10}$ Granulomatous inflammation was diagnosed in none of the cases on BMA and BMI smears in the present study (Figure 3). This is mainly because of focal involvement of

Table 1. Cases diagnosed on bone marrow aspirate, imprint cytology and trephine biopsy.

\begin{tabular}{lcccc} 
Diagnosis & $\begin{array}{c}\text { Total } \\
\text { cases }\end{array}$ & $\begin{array}{c}\text { Bone } \\
\text { marrow } \\
\text { aspirate } \\
\text { cytology }\end{array}$ & $\begin{array}{c}\text { Bone } \\
\text { marrow } \\
\text { imprint } \\
\text { cytology }\end{array}$ & $\begin{array}{c}\text { Bone } \\
\text { marrow } \\
\text { trephine } \\
\text { biopsy }\end{array}$ \\
\hline Nutritional anemia & 146 & 144 & 146 & 146 \\
Granulomatous inflammation & 6 & - & - & 6 \\
\hline Infections & 12 & 12 & 12 & 12 \\
Malarial & 4 & 4 & 4 & 4 \\
\hline Fungal & 1 & 1 & 1 & 1 \\
Leishmaniasis & 7 & 7 & 7 & 7 \\
\hline Immune thrombocytopenia & 14 & 8 & 11 & 14 \\
Anemia of chronic disorders & 22 & 22 & 12 & 18 \\
\hline Hematological malignancies & 120 & 111 & 117 & 120 \\
Acute myeloid leukemia & 54 & 50 & 54 & 54 \\
\hline Acute lymphoid leukemia & 20 & 18 & 20 & 20 \\
Chronic myeloid leukemia & 29 & 26 & 26 & 29 \\
\hline Chronic lymphoid leukemia & 17 & 17 & 17 & 17 \\
Follow up cases of hematological malignancies & 18 & 16 & 17 & 18 \\
\hline Morphological remission & 7 & 7 & 7 & 7 \\
Incomplete remission & 11 & 9 & 10 & 11 \\
\hline Multiple myeloma & 20 & 19 & 20 & 20 \\
Lymphoma & 17 & 9 & 15 & 17 \\
\hline Myelodysplastic syndrome & 12 & 10 & 11 & 12 \\
Metastatic solid tumors & 30 & 21 & 28 & 30 \\
\hline Hypoplastic / Aplastic anemia & 56 & - & - & 56 \\
Normal bone marrow & 12 & 58 & 75 & 80 \\
\hline Miscellaneous & 565 & 8 & 9 & 12 \\
Total & & 438 & 473 & 561 \\
\hline & 12 & & \\
\hline
\end{tabular}

Table 2. Cases showing positive correlation of bone marrow aspirate cytology and imprint cytology with trephine biopsy.

$\begin{array}{cc}\begin{array}{c}\text { Positive correlation } \\ \text { of BMA cytology }\end{array} & \begin{array}{c}\text { Positive correlation } \\ \text { of BMI cytology } \\ \text { and BMB ( } \% \text { of cases) }\end{array} \\ \text { and BMB ( } \% \text { of cases) }\end{array}$

\begin{tabular}{lcc} 
Nutritional anemia & 98.6 & 100 \\
Granulomatous inflammation & 00 & 00 \\
\hline Infections & 100 & 100 \\
Immune thrombocytopenia & 57.1 & 78.5 \\
\hline Anemia of chronic disorder & 81.8 & 66.6 \\
Hematological malignancies & 92.5 & 97.5 \\
\hline Follow up cases of hematological malignancies & 88.8 & 94.4 \\
Multiple myeloma & 95 & 100 \\
\hline Lymphoma & 52.9 & 88.2 \\
Myelodysplastic syndrome & 83.3 & 91.6 \\
\hline Metastatic solid tumors & 70 & 93.3 \\
Hypoplastic/Aplastic anemia & 00 & 00 \\
\hline Normal bone marrow & 72.5 & 93.7 \\
Miscellaneous & 66.6 & 75 \\
\hline Total & 78 & 84.3
\end{tabular}


the marrow by granulomas which is very difficult to be detected on aspirate and imprint smears. However this limitation can be overcome by performing bilateral trephine biopsy procedure so that chances of detecting granulomas on imprint smears could be increased but in the present study none of the case of granulomatous inflammation had bilateral bone marrow examination. Other studies have also observed the detection of granulomas more on BMB sections in comparison to aspirate smears. ${ }^{2,11}$ For diagnosing of hematological malignancies the BMA and BMI smears were almost as reliable as BMB, however, with slightly higher detection rate by BMI ( $97.5 \%)$ in comparison to BMA (92.5\%). The predominant reason for not diagnosing leukemia on BMA was dry tap due to either marrow fibrosis or tightly packed marrow by leukemic cells. Aboul Nasr R et al. have also observed that BMI cytology was reliable for making diagnosis of hema- tological malignancies especially in cases of dry tap due to fibrosis or dilution of aspirate by peripheral blood. ${ }^{7}$ BMB remains the gold standard for diagnosing hypoplastic/ aplastic anemia with none of the cases being diagnosed on aspirate and imprint smears. Although $89.2 \%$ cases showed hypocellular marrow/dry tap on BMA or BMI due to marrow fibrosis but the confirmation of fibrosis by reticulin stain was possible only on trephine biopsy.

The authors further suggest that the adequacy of touch imprint smears in diagnosing most of the hematological disorders may be related to meticulously prepared imprint smears which requires not only gentle touch of the biopsy core on slides to prevent crush artifact but also preparation of touch smears by gentle rolling the core so that impression of the cells are made by almost all aspects of the core biopsy. This procedure will enhance the detection of focal involvement marrow also. In

Table 3. Cases where findings on Bone marrow aspirate cytology, touch imprint cytology or trephine biopsy differed from final diagnosis.

\begin{tabular}{|c|c|c|c|c|c|c|}
\hline Diagnosis & $\begin{array}{c}\text { BMA } \\
\text { cytology }\end{array}$ & $\begin{array}{l}\text { No. } \\
\text { of cases }\end{array}$ & $\begin{array}{c}\text { BMI } \\
\text { cytology }\end{array}$ & $\begin{array}{l}\text { No. } \\
\text { of cases }\end{array}$ & $\begin{array}{c}\text { BMB } \\
\text { sections } 0\end{array}$ & $\begin{array}{l}\text { No. } \\
\text { f cases }\end{array}$ \\
\hline Nutritional anemia & Failed aspiration & 2 & & & & \\
\hline $\begin{array}{l}\text { Granulomatous } \\
\text { inflammation }\end{array}$ & Normal marrow & 6 & Normal marrow & & & \\
\hline $\begin{array}{l}\text { Immune } \\
\text { thrombocytopenia }\end{array}$ & Dry tap & 2 & $\begin{array}{l}\text { Megakaryocytes } \\
\text { appear normal }\end{array}$ & 3 & - & \\
\hline $\begin{array}{l}\text { Anemia of chronic } \\
\text { disorder }\end{array}$ & - & - & $\begin{array}{l}\text { No iron or } \\
\text { reduced } \\
\text { stainable iron } \\
\text { seen }\end{array}$ & 10 & $\begin{array}{l}\text { No iron } \\
\text { seen }\end{array}$ & 4 \\
\hline $\begin{array}{l}\text { Chronic myeloid } \\
\text { leukemia }\end{array}$ & $\begin{array}{l}\text { Dry tap due } \\
\text { to fibrosis }\end{array}$ & 3 & $\begin{array}{l}\text { Hypocellular } \\
\text { marrow }\end{array}$ & 3 & + & \\
\hline $\begin{array}{l}\text { Acute myeloid } \\
\text { leukemia }\end{array}$ & $\begin{array}{l}\text { Dry tap due to } \\
\text { packed marrow }\end{array}$ & 4 & - & - & - & \\
\hline $\begin{array}{l}\text { Acute lymphoid } \\
\text { leukemia }\end{array}$ & $\begin{array}{l}\text { Dry tap due to } \\
\text { packed marrow }\end{array}$ & 2 & - & - & - & \\
\hline Incomplete remission & $\begin{array}{l}\text { Morphological } \\
\text { remission }\end{array}$ & 2 & $\begin{array}{l}\text { Morphological } \\
\text { remission }\end{array}$ & 1 & - & \\
\hline Multiple myeloma & Dry tap & 1 & - & - & - & \\
\hline Lymphoma & $\begin{array}{l}\text { Normal marrow } \\
\text { Hypocellular } \\
\text { marrow } \\
\text { Atypical cells }\end{array}$ & $\begin{array}{l}4 \\
2 \\
2\end{array}$ & $\begin{array}{c}\text { Normal marrow } \\
\text { Hypocellular } \\
\text { marrow }\end{array}$ & $\begin{array}{l}1 \\
1\end{array}$ & & \\
\hline Myelodysplastic syndrome & $\begin{array}{l}\text { Megaloblastic } \\
\text { anemia }\end{array}$ & 2 & $\begin{array}{l}\text { Megaloblastic } \\
\text { anemia }\end{array}$ & 1 & - & \\
\hline $\begin{array}{l}\text { Hypoplastic/ } \\
\text { Aplastic anemia }\end{array}$ & $\begin{array}{c}\text { Dry tap } \\
\text { Hypocellular marrow } \\
\text { Normal marrow }\end{array}$ & $\begin{array}{r}30 \\
20 \\
6\end{array}$ & $\begin{array}{l}\text { Hypocellular } \\
\text { marrow } \\
\text { Normal marrow }\end{array}$ & $\begin{array}{l}50 \\
6\end{array}$ & - & \\
\hline Normal bone marrow & $\begin{array}{c}\text { Hypocellular marrow } \\
\text { Dry tap } \\
\text { Lymphocytosis } \\
\text { Plasmacytosis }\end{array}$ & $\begin{array}{l}4 \\
3 \\
8 \\
7\end{array}$ & $\begin{array}{c}\text { Lymphocytosis } \\
\text { Hypocellular marrow }\end{array}$ & $\begin{array}{l}3 \\
2\end{array}$ & - & \\
\hline Metastatic solid tumors & $\begin{array}{c}\text { Normal marrow } \\
\text { Hypocellular marrow } \\
\text { Dry tap }\end{array}$ & $\begin{array}{l}6 \\
2 \\
1\end{array}$ & $\begin{array}{l}\text { Normal marrow } \\
\text { Hypocellular marrow }\end{array}$ & $\begin{array}{l}1 \\
1\end{array}$ & - & \\
\hline Miscellaneous & $\begin{array}{c}\text { Normal marrow } \\
\text { Hypocellular marrow }\end{array}$ & $\begin{array}{l}2 \\
2\end{array}$ & $\begin{array}{c}\text { Normal marrow } \\
\text { Hypocellular marrow }\end{array}$ & $\begin{array}{l}2 \\
1\end{array}$ & & \\
\hline
\end{tabular}

addition it may also avoid the unnecessary delay caused by decalcification and processing of trephine biopsy sections in routine histopathology labs.

\section{Conclusions}

The study concludes that all the three preparations of aspirate cytology, touch imprint cytology and trephine biopsy complement each other for evaluating any bone marrow. The

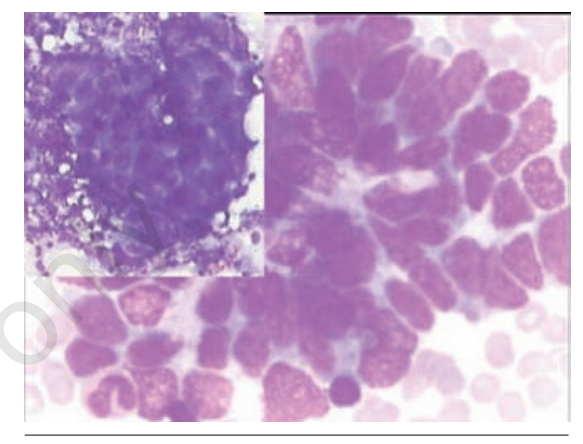

Figure 1. Bone marrow imprint smears showing metastatic solid tumor cells (x400, Jenner Giemsa; inset-x100, Jenner Giemsa).

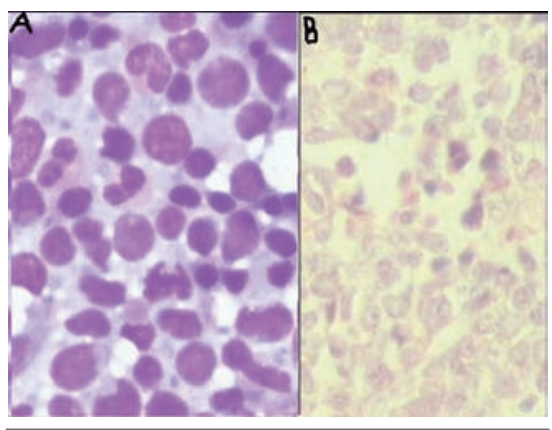

Figure 2. A) Bone marrow imprint smear showing involovement by Non Hodgkin's lymphoma (x400, Jenner Giemsa); B) Bone marrow trephine biopsy showing diffuse involvement by Non Hodgkin's lymphoma (x100, Hematoxyline Eosin).

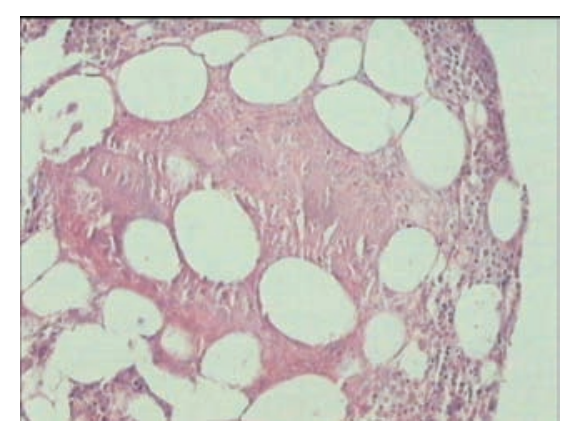

Figure 3. Bone marrow trephine biopsy showing granuloma (x100, Hematoxyline Eosin). 
assessment of iron status by Perl's stain is although not adequate on biopsy sections in comparison to aspirate smears but trephine biopsy remains the gold standard for diagnosing granulomatous inflammation and hypoplastic/ aplastic anemia. Vigilant examination of aspirate smears and meticulously prepared imprint cytology smears are almost equally efficient and more rapid method for diagnosis metastatic solid tumors in comparison to trephine biopsy. Appropriately prepared imprint cytology smears do not only adequately provide cellular composition of marrow but may also define the topographical architecture of marrow. Imprint cytology smears should therefore be standard practice for evaluating any marrow.

\section{References}

1. Chandra S, Chandra H, Saini S. Bone marrow metastasis by solid tumors - probable hematological indicators and comparison of bone marrow aspirate, touch imprint and trephine biopsy. Hematology 2010; 15:368-72.

2. Nanda A, Basu S, Marwaha N. Bone marrow trephine biopsy as an adjunct to bone marrow aspiration. J Assoc Physicians India 2002;50:893-5.

3. Gupta R, Setia N, Arora P, et al. Hematological profile in pyrexia of unknown origin: role of bone marrow trephine biopsy vis-à-vis aspiration. Hematology 2008;13:307-12.

4. Moid F, DePalma L. Comparison of relative valve of bone marrow aspirates and bone marrow trephine biopsies in the diagnosis of solid tumor metastasis and Hodgkin's Lymphoma - Institutional experience and literature review. Arch Pathol Lab Med 2005;129:497-501.

5. Sabharwal BD, Malhotra VV, Aruna SS, Grewal RR. Comparitive evaluation of bone marrow aspirate particle smears, imprints and biopsy sections. J Postgrad Med 1990;36:194-8.

6. Donald P, Chikappa G. Comparative evaluation of bone marrow aspirate particle smears biopsy imprints and biopsy sec- tions. Am J Hematology 1986;22:381-9.

7. Aboul-Nasr R, Estey EH, Kantarjian HM, et al. Comparison of touch imprints with aspirate smears for evaluating bone marrow specimens. Am J Clin Pathol 1999;111: 753-8.

8. Barekman CL, Cotelingam JD. Compa rison of touch imprints with aspirate smears for evaluating bone marrow specimens. Am J Clin Pathol 2001;116:945-8.

9. Pasquale D, Chikkappa G. Comparitive evaluation of bone marrow aspirate particulate smears, biopsy imprints and biopsy sections. Am J Haematol 1986;22:381-9.

10. Varma N, Dash S, Sarode R, Marwaha N. Relative efficacy of bone marrow trephine biopsy sections as compared to trephine imprints and aspiration smears in routine hematolgocial practice. Indian J Pathol Microbiol 1993;36:215-26.

11. Ch Toi P, Varghese G'Boy R, Rai R. Comparitive evaluation of simultaneous bone marrow aspiration and bone marrow biopsy. An institutional experience. Indian J Hematol Blood Transfus 2010;26:41-4. 